\title{
COMIDA DE QUILOMBO NA MERENDA ESCOLAR: INTERFACES ENTRE A CULTURA ALIMENTAR E O PROGRAMA NACIONAL DE ALIMENTAÇÃO ESCOLAR
}

Nádia Alinne Fernandes Corrêa $ه$

Universidade Federal do Pará/Programa de Pós-Graduação

em Antropologia | Belém - PA - Brasil

Luis Fernando Cardoso e Cardoso (D) $\triangle$

Universidade Federal do Pará/Programa de Pós-Graduação

em Ciência Política I Belém - PA - Brasil

\author{
Hilton P. Silva (1) $ه$
}


RESUMO

O Programa Nacional de Alimentação Escolar (PNAE) objetiva contribuir para o desenvolvimento biopsicossocial, o rendimento escolar e a formação de hábitos alimentares saudáveis nas escolas públicas brasileiras, mas, em território quilombola, a oferta das refeições pelo programa, muitas vezes, conflita com a história e a identidade alimentar dos grupos. Neste artigo, analisamos a relação do quilombo de Umarizal, Baião, Pará, com a merenda escolar, mostrando como os sujeitos locais percebem o programa e como ele participa da realidade sociocultural local. Para isso, usamos metodologias qualitativas, como observação direta, entrevistas e grupo focal. Os dados foram analisados segundo os parâmetros da pesquisa etnográfica. Os resultados evidenciam que há uma descontinuidade entre o PNAE e a cultura alimentar do quilombo, causando descompasso entre o alimento oferecido na escola e a cultura local. Cumpre corrigir esse desencontro para equalizar as oportunidades ao aprendizado dos estudantes em todo o país.

Palavras-chave: comunidade quilombola; cultura alimentar; PNAE; Amazônia; saúde da população negra.

\section{QUILOMBO FOOD IN SCHOOL MEALS: INTERFACES BETWEEN THE FOOD CULTURE AND THE NATIONAL SCHOOL FEEDING PROGRAM}

\section{ABSTRACT}

The National School Feeding Program (PNAE) aims to contribute to the biopsychosocial development, school performance and the formation of healthy eating habits in Brazilian public schools. However, in quilombola territory, the offer of meals by the program often conflicts with the groups' history and food identity. In this article, we analyze the relationship between the quilombo of Umarizal (Baião, Pará) and the school meals, and discuss how local individuals perceive the program and how it participates in the local sociocultural reality. For this, qualitative methodology such as direct observation, interviews, and focus group was used. Data were analyzed according to ethnographic research parameters. The results show that there is a discontinuity between the PNAE and the quilombo food culture, causing a mismatch between the food offered at school and the local culture. This flaw needs to be corrected to promote equal learning opportunities for the students across the country.

Keywords: quilombola community; food culture; PNAE; Amazon; health of the black population.

\section{COMIDA DE QUILOMBO EN LA MERIENDA ESCOLAR: INTERFACES ENTRE LA CULTURA ALIMENTARIA Y EL PROGRAMA NACIONAL DE ALIMENTACIÓN ESCOLAR}

\section{RESUMEN}

El Programa Nacional de Alimentación Escolar (PNAE) tiene como objetivo contribuir al desarrollo biopsicosocial, al rendimiento escolar y a la formación de hábitos alimenticios saludables en las escuelas públicas brasileñas. Sin embargo, en el territorio quilombola, la oferta de comidas del programa a menudo entra en conflicto con la historia y la identidad alimentaria de los grupos. En este artículo, analizamos la relación entre el quilombo Umarizal, Baião (PA) y la "merienda escolar”, mostrando cómo perciben el programa las personas locales y cómo este participa en la realidad sociocultural local. Para tal fin, se utilizó el método cualitativo con observaciones directa, entrevistas y grupos focales. Los datos fueron analizados de acuerdo con los parámetros de investigación etnográfica. Los resultados muestran que existe una discontinuidad entre el PNAE y el cultivo alimentario del quilombo, lo que provoca un desequilibrio entre el alimento ofrecido en la escuela y la cultura local. Este desequilibrio debe corregirse para igualar las oportunidades de aprendizaje de los estudiantes en todo el país.

Palabras clave: comunidad quilombola; cultura alimentaria; PNAE; Amazonas; salud de la población negra. 


\section{INTRODUÇÃO}

Os grupos negros rurais, por muitos anos, estiveram invisíveis para as políticas públicas. As assistências médica e escolar, bem como o acesso à produção agrícola, ao saneamento ambiental, à energia elétrica, à água potável e às outras ações que imprimem cidadania ao povo brasileiro têm sido negados aos territórios quilombolas (Oliveira et al. 2018). Embora a materialização dos direitos sociopolíticos, territoriais, educacionais e de saúde seja garantida desde a Constituição Federal de 1988, até o momento, esses direitos não foram efetivados para a maioria dos quilombos (Brasil 1988; Oliveira et al. 2018).

O artigo 68 do Ato das Disposições Constitucionais e Transitórias (ADCT) estabeleceu o respeito ao direito dos quilombolas às suas terras tradicionalmente ocupadas, impulsionando-os a construírem estratégias de ação, como a organização em movimentos sociais locais e em redes - parcerias políticas e institucionais -, e assegurando-lhes o reconhecimento nacional e internacional de suas reivindicações, as quais começaram a surgir a partir dos anos 2000 (A. Silva 2018). O artigo 68 foi valoroso não apenas por garantir direitos territoriais, mas também por ter sido um marco histórico no projeto político das populações negras no país (Arruti 2008; Leite 2008).

No decorrer da história, as pautas do movimento social ampliaram-se, sendo inseridas na agenda nacional as primeiras políticas de promoção da igualdade racial, com medidas que visavam à qualidade de vida da população negra. As novas temáticas integraram os eixos do Programa Brasil Quilombola e da Agenda Social Quilombola (Rodrigues 2010). No bojo dessas iniciativas, o Programa Nacional de Alimentação Escolar (PNAE) específico para quilombolas, o PNAQN, e o Programa Mais Educação Quilombola, o PN+QN, foram inseridos como instrumentos fortalecedores de direitos e de cidadania. Com isso, por meio da promulgação da Lei n. 11.947/2009, as escolas passaram a ser estimuladas a adquirir alimentos dos locais em que se situam, respeitando a cultura e os recursos naturais presentes nesses territórios (Brasil 2009).

A partir de então, o fornecimento da "merenda" às escolas da rede pública de ensino deveria assegurar uma alimentação compatível com as práticas alimentares tradicionais de indígenas e quilombolas beneficiados pelo programa. Para tanto, houve a elaboração de mecanismos especiais de orçamento, planejamento, geração de emprego

1 "Merenda escolar" é o nome pelo qual o programa PNAE é conhecido popularmente no país. 
e de renda, conforme estipulado no valor per capita ${ }^{2}$, segundo o qual as demandas nutricionais específicas para a confecção de cardápios são superiores às necessidades referentes aos demais alunos do município, pelo fato de os estudantes dos grupos étnicos estarem em situação de maior vulnerabilidade quando comparados aos outros estudantes do país (E. Silva et al. 2017). Além disso, priorizam-se os contratos de compra e venda de produtos dos agricultores familiares como forma de estimular a economia nessas localidades (Sousa et al. 2013; Carvalho \& Oliveira e Silva 2014).

Em muitos estados brasileiros, no entanto, são evidentes a incompatibilidade entre a oferta de alimentação adequada e saudável e os hábitos dos quilombolas assistidos pelo PNAE. Essa dificuldade deve-se, em geral, à incompreensão dos gestores municipais a respeito dos hábitos alimentares culturalmente diferenciados, etnicamente marcados e socialmente construídos como identidades de resistência ante as lógicas englobantes da sociedade brasileira (Brasil 2009; CAISAN 2017).

A organização sociocultural das comunidades quilombolas apresenta configurações próprias, constantemente desprezadas na formulação dos cardápios escolares (Sousa et al. 2013; Santana Filho \& Cerqueira 2017). Nesse sentido, buscou-se compreender a relação do quilombo de Umarizal, Baião, Pará, com a merenda escolar, mostrando como os sujeitos locais percebem o programa e como o PNAE participa da realidade sociocultural local.

Para entender esta realidade, foi utilizada metodologia qualitativa com pesquisa de campo (Duarte 2004; Brandão 2010; Sánchez Parga 2010; Bernard 2011), observação direta (Chauvin \& Jounin 2015), entrevistas (Barbot 2015) e aplicação de grupo focal (L. Souza 2020) ao corpo administrativo e aos docentes da Escola Municipal de Ensino Fundamental de Umarizal.

A fase inicial da investigação ocorreu por meio de uma rede de relações construídas a partir do presidente da Associação Quilombola de Umarizal. Participaram do estudo 24 docentes e dois funcionários do quadro administrativo, dos quais 21 eram mulheres e cinco eram homens. Dadas as implicações políticas deste artigo, optouse pelo anonimato dos participantes, referindo-se a eles apenas pela terminologia "docente", seguida do número de identificação do sujeito no estudo.

\section{ALIMENTAÇÃO COMO PRÁTICA CULTURAL}

A comida deve ser culturalmente aceita para ser ingerida (Jaramillo 2012). Essa observação evidencia o caráter fundamental do alimento, não

2 Valor de R\$ 0,64 (sessenta e quatro centavos de real) repassado pela União a estados e municípios, por dia letivo, para cada aluno indígena ou quilombola, enquanto para aos demais alunos o valor é $\mathrm{R} \$ 0,36$ (trinta e seis centavos de real) (Brasil 2017). 
apenas em termos nutricionais, mas também na organização, na percepção e na estrutura da vida social dos grupos. Nesse contexto, as práticas alimentares seriam o resultado das crenças e dos tabus, das preferências e das repulsas, dos rituais, do simbolismo, das classificações, entre outros aspectos submersos em sistemas de significados, capazes de influenciar as decisões sobre o que, quando, onde e com quem comer, regulando o comportamento e a ingestão alimentar (Geertz 1978; Certeau 2009).

A alimentação humana, nesse sentido, está submetida a um processo coletivo, cujos participantes são integralmente afetados pelo peso dos juízos culturais presentes na organização social dos diversos grupos. Por isso, sem desmerecer a importância das necessidades biológicas, de acordo com Montanari (2013), todos os processos que envolvem o ato de comer são culturais.

Comida é cultura quando produzida, porque o homem não utiliza apenas o que encontra na natureza (como fazem todas as espécies de animais), mas ambiciona também criar a própria comida, sobrepondo a atividade de produção à de predação. Comida é cultura quando preparada, porque, uma vez adquiridos os produtosbase da sua alimentação, o homem os transforma mediante o uso do fogo e de uma elaborada tecnologia que se exprime nas práticas da cozinha. Comida é cultura quando consumida, porque o homem, embora possa comer de tudo, ou talvez justamente por isso, na verdade, não coma qualquer coisa, mas escolha a própria comida, com critérios ligados tanto às dimensões econômicas e nutricionais do gesto quanto aos valores simbólicos de que a própria comida consumida se reveste (Montanari 2013:16, grifos nossos).

Nesse caminho, a percepção dos aspectos culturais impõe diferenças entre a comida e o alimento. O antropólogo Roberto DaMatta (1987:4) procura separar esses fenômenos, afirmando que "toda substância nutritiva é alimento, mas nem todo alimento é comida”. O autor destaca o caráter universal do alimento como algo inerente à vida dos seres humanos e o caráter simbólico que a comida teria na distinção de um grupo, classe ou pessoa. Outro autor - Fischler (1995:20) também constrói paralelos sobre o ato alimentar, ao criar valores distintos para os nutrientes. Em suas palavras, o "homem nutre-se de nutrientes, mas também de imaginários que são partilhados socialmente"; assim, existem os valores nutritivo - caracterizado pela necessidade da ingestão de glicídios, lipídios, proteínas, sais minerais, vitaminas e água - e simbólico - tido como algo que dá sentido ao que se está ingerindo.

Essas considerações representam esforços teóricos dos antropólogos para criar, desde o século passado, o campo de estudos da alimentação, que tem sido continuamente desafiado a compreender as mudanças nos hábitos alimentares da sociedade (Contreras 1992). 
Na contemporaneidade, devido à globalização, a estrutura e a composição das refeições diárias têm mudado, desconectando as populações de suas formas tradicionais de consumo, criando, assim, modelos de alimentação padronizados e homogeneizados, ditados pelas indústrias de alimentos, com impactos negativos na saúde (Dufour \& Bender 2013).

Para Poulain (2004), o desafio está na releitura dessa desconexão, a fim de se compreender como os movimentos sociais podem favorecer a recomposição das culturas alimentares. Entender os processos pelos quais diferentes comunidades criam modelos e, ao mesmo tempo, conservam traços específicos de sua cultura abre diálogos para o estudo da construção das identidades em torno do alimento.

A identidade social refere-se a um processo dialético entre a maneira como nós nos percebemos e a maneira como somos percebidos pelos outros (Hall $\&$ du Gay 1996). Isso pode ser entendido como algo que liga o sujeito à estrutura sociocultural, estando, para Contreras (1992), presente nas maneiras como são preparados e servidos os alimentos, na forma como são concebidos e compartilhados e também como eles são ou não utilizados. Portanto, muito do comportamento alimentar projetado seria uma forma de expressar as identidades individuais ou coletivas em uma dada sociedade.
A alimentação é uma parte da identidade social de um povo (Braga 2004). As cozinhas, por sua vez, são espaços de resistência e de demarcação dessas identidades diante de processos de mudanças (Maciel \& Castro 2013). Para Maciel \& Castro (2013), tais processos ocorrem pela complexificação do ato de se alimentar, com a absorção de elementos novos pela cozinha tradicional, a qual ressignifica o que lhe era estranho. A identidade é parte de um projeto coletivo que está em constante reconstrução e que alia o tradicional e o moderno.

As cozinhas, assim, surgem como uma nova formulação das diversidades culturais, valorizando as especialidades alimentares da terra, aquelas ligadas aos costumes, às crenças e às tradições. Essa concepção da particularidade local também tornouse área de continuidade histórica e consciência de pertença comum, fazendo com que as identidades conjuguem da solidariedade territorial, bem como do vínculo espacial e memorial (Flandrin \& Montanari 2018).

É o caso das comunidades quilombolas, que têm a sua identidade ligada à ideia de pertencimento. Nelas, há uma identidade coletiva, na qual os laços são construídos com base em valores, costumes e lutas comuns, cujos elementos estruturais tornam esse grupo diferente dos demais. Na formação dessas comunidades, destaca-se a predominância de uma população negra, porém também são 
observadas relações interétnicas estabelecidas com não negros, o que rompe com a redução da identidade a traços biológicos, como a cor da pele (B. Souza 2016).

As comunidades quilombolas são identidades étnicas orientadas para o passado, definidas a partir de uma memória coletiva (Halbwachs 2013). Por serem grupos que carregam uma memória do sistema escravocrata, apresentam conotação de identidade histórica. No entanto, é preciso ter cuidado quando se considera tal informação, pois o passado, ao ser invocado, deve corresponder a uma forma atual de existência, ou seja, deve ser uma memória presente no cotidiano de seus moradores (O'Dwyer 2002).

Sobre os alimentos identitários, diversos estudos têm ressaltado que as fontes alimentares de subsistência estão presentes no próprio território em que se vive (D. Silva et al. 2008; Carvalho \& Oliveira Silva 2014; Nascimento \& Guerra 2016; Santos \& Garavello 2016). As narrativas têm como base o cuidado com a cultura local e, em relação aos grupos étnicos, as memórias coletivas. Portanto, os alimentos descritos como identitários marcam a história de cada lugar e de cada grupo, o que nos permite não confundir alimentos identitários com a representação de uma "única" categoria étnica como "os quilombolas" (Barth 2005).

\section{O PNAE EM UMARIZAL}

A vila de Umarizal ${ }^{3}$, localizada no município de Baião, está situada à margem do rio Tocantins. Vivem, na comunidade, aproximadamente, 200 famílias, que são servidas por uma unidade básica de saúde e uma escola. A Escola Municipal de Ensino Fundamental (EMEF) Umarizal recebe recursos do Programa Nacional de Alimentação Escolar Quilombola para atender 387 alunos $^{4}$ dos "anos iniciais" (da $1^{\mathrm{a}}$ à $4^{\mathrm{a}}$ série ou do $1^{\circ}$ ao $5^{\circ}$ ano), dos “anos finais" (da $5^{\mathrm{a}}$ à $8^{\mathrm{a}}$ série ou do $6^{\circ}$ ao $9^{\circ}$ ano) e da Educação de Jovens e Adultos. O número de alunos matriculados na escola equivale a $26,07 \%$ do total de estudantes quilombolas do município $(\mathrm{N}=1.484)^{5}($ FNDE 2019).

O cardápio planejado pela gestão municipal para alimentar os alunos durante 20 dias letivos leva em consideração dez preparações, subdivididas entre refeições doces e salgadas. Conforme observado no Quadro 1, os lanches doces, como sucos, bebidas achocolatadas ou mingaus, estavam previstos para

3 Essa localidade foi certificada pela Fundação Cultural Palmares em 2006. Com outras quatro comunidades - Boa Vista, Florestão, Paritá Miri e Umarizal Centro -, forma o território quilombola de Umarizal.

4 De acordo com o Censo Escolar de 2019.

5 O município de Baião tem 27 comunidades quilombolas. Em comparação aos outros municípios paraenses, é o segundo maior em quantidade de quilombos do Pará. 
serem servidos três vezes na semana - todas as segundas, quartas e sextas-feiras; já os salgados, como as sopas ou as próprias refeições, reduziamse às terças e quintas-feiras.

Quadro 1 - Preparações realizadas no PNAQN da EMEF Umarizal, Baião, Pará. Dados coletados na pesquisa de campo realizada em 2019

\begin{tabular}{|c|c|}
\hline Tipos de preparações & $\begin{array}{l}\text { Dias da semana em } \\
\text { que são oferecidas }\end{array}$ \\
\hline \multicolumn{2}{|c|}{ Preparações doces } \\
\hline $\begin{array}{l}\text { Achocolatado com leite e } \\
\text { biscoito tipo salgado }\end{array}$ & \multirow{5}{*}{$\begin{array}{l}\text { Segundas, quartas e } \\
\text { sextas-feiras }\end{array}$} \\
\hline $\begin{array}{c}\text { Mingau de arroz com } \\
\text { farinha de tapioca, leite em } \\
\text { pó e açúcar }\end{array}$ & \\
\hline $\begin{array}{l}\text { Mingau de milho branco, } \\
\text { arroz, farinha de tapioca, } \\
\text { leite em pó e açúcar }\end{array}$ & \\
\hline $\begin{array}{l}\text { Suco de polpa de fruta com } \\
\text { biscoito doce }\end{array}$ & \\
\hline $\begin{array}{l}\text { Suco de polpa de fruta com } \\
\text { biscoito salgado }\end{array}$ & \\
\hline \multicolumn{2}{|c|}{ Preparações salgadas } \\
\hline $\begin{array}{l}\text { Arroz com charque, mamão } \\
\text { e temperos }\end{array}$ & \multirow{5}{*}{ Terças e quintas-feiras } \\
\hline $\begin{array}{l}\text { Frango desfiado com arroz, } \\
\text { feijão, cenoura e temperos }\end{array}$ & \\
\hline $\begin{array}{c}\text { Sopa de charque com arroz, } \\
\text { feijão, cenoura, temperos e } \\
\text { mamão }\end{array}$ & \\
\hline $\begin{array}{l}\text { Sopa de charque com } \\
\text { macarrão, cenoura, } \\
\text { temperos e mamão }\end{array}$ & \\
\hline $\begin{array}{l}\text { Sopa de frango desfiado } \\
\text { com macarrão, feijão, } \\
\text { cenoura, temperos e } \\
\text { mamão }\end{array}$ & \\
\hline
\end{tabular}

Como pode ser observado, os alimentos servidos aos estudantes de Umarizal estão distantes dos hábitos alimentares saudáveis: há achocolatados, farinha de tapioca industrializada, frango desfiado industrializado, charque e biscoitos.

Apesar dos desvirtuamentos por muitas administrações municipais em território nacional, o programa de alimentação escolar é referência mundial na garantia do direito humano à alimentação adequada. Ele é norteado pelos princípios da promoção da saúde e segurança alimentar, da defesa dos sistemas agroalimentares sustentáveis, da cultura e da soberania alimentar. Como parte integrante da educação, seu formato foi desenvolvido para facilitar o aprendizado e a formação de hábitos saudáveis (Brasil 2013, 2018; E. Silva et al. 2018).

A Lei n. 11.947/2009 e a Resolução CD/FNDE n. 26/2013 garantem às escolas quilombolas recursos financeiros diferenciados, que são repassados pelo Governo Federal, porque estão nas piores condições socioeconômicas e de segurança alimentar no país. A merenda escolar quilombola deve atingir, no mínimo, 30\% das necessidades nutricionais diárias, o que é superior em $10 \%$ ao estipulado para os alunos não quilombolas matriculados em período parcial (Brasil 2013).

Os dados da Pesquisa Nacional de Saúde do Escolar (PeNSE), realizada em escolas em todo o país em 2015, constataram o elevado consumo semanal de alimentos ultraprocessados, especialmente guloseimas $(50,9 \%)$, refrigerantes $(37,2 \%)$, biscoitos doces 
$(33,6 \%)$ e embutidos (18\%) (IBGE 2016). Esses produtos estão associados a doenças crônicas não transmissíveis, como sobrepeso, obesidade, diabetes e alergias. Já o consumo de salsicha, presunto, salame, mortadela, carne-seca - ou charque - e carne enlatada pode aumentar o risco de desenvolvimento de câncer, principalmente de câncer colorretal (Cordeiro et al. 2014; Bouvard et al. 2015).

Dada a importância da saúde dos alunos para a formação de adultos saudáveis, é necessário que existam ações educativas ao longo do currículo escolar abordando os temas da alimentação e da nutrição. Independente do local onde os alimentos industrializados são oferecidos no ambiente escolar - se em cantinas ou em refeitórios -, é preciso reverter o baixo consumo de frutas e hortaliças, associado à excessiva utilização de insumos cuja qualidade nutricional é inferior à do conjunto dos demais alimentos (Brasil 2012; Sousa et al. 2013).

\section{ALIMENTO, COMIDA E CULTURA}

\section{PARA OS QUE MERENDAM}

A alimentação reflete a cultura de uma sociedade: "cada grupo social possui um quadro de referências que guia a escolha de seus alimentos" (Contreras \& Gracia 2011). É nesse sentido que o aspecto cultural tem sido enfatizado na alimentação escolar, como forma de buscar entender os significados das preferências e das aversões dos alunos. Essa compreensão tem levado, nos últimos anos, o Fundo Nacional de Desenvolvimento da Educação (FNDE) a acentuar a preocupação com o aspecto cultural na formulação da merenda escolar.

Em 2015, o FNDE lançou o primeiro curso sobre "Alimentação escolar indígena e quilombola", como forma de instrumentalizar os responsáveis técnicos pelo PNAE dos estados e municípios para que pudessem adequar os cardápios escolares à cultura e à tradição alimentares dos grupos sociais brasileiros. O curso tinha como imperativos discutir as seguintes questões entre os participantes:

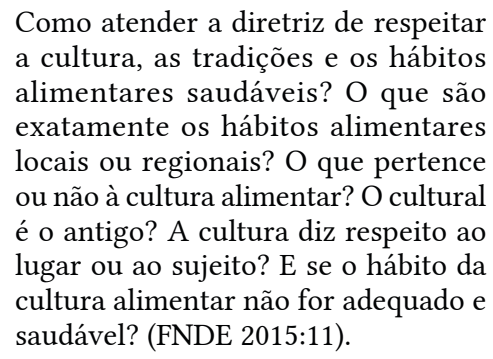

As questões foram motivadas pelo parágrafo $6^{\circ}$, do artigo 14, da Resolução n. 26/2013, segundo o qual “os cardápios deverão atender as especificidades culturais das comunidades indígenas e/ou quilombolas" (Brasil 2013). O dispositivo surgiu 
estrategicamente em um contexto de globalização ${ }^{6}$, como incentivo à desaceleração dos processos de massificação dos gostos, de homogeneização de identidades e de riscos para a realidade cultural das populações, em especial para as comunidades tradicionais.

Em diálogo com os sujeitos da escola de Umarizal a respeito da comida que é servida aos alunos, eles expressaram, de maneira geral, que há um descaso com o que é servido aos estudantes. Essa situação está em descontinuidade com os esforços realizados no passado, para que houvesse uma conexão entre os saberes, as práticas e os esforços locais, com o intuito de garantir uma alimentação de qualidade e culturalmente adequada. É o que se deduz dos trechos de falas que exprimem a situação vivida na comunidade (Quadro 2).

Quadro 2 - Relatos consensuados entre os docentes sobre a alimentação oferecida na EMEF Umarizal, coletados em pesquisa de campo realizada em 2020.

"Aqui nunca foi feito feijão, pois as meninas da cozinha acham que dá trabalho."

"O mingau de arroz, a gente não gosta, porque aqu tem que levar o açaí."

"O nosso mingau de açaí é salgado; esse mingau papa, branco e doce ninguém come."

"O suco da merenda já é conhecido [entre os alunos] como água da beira da estrada.”

“Os alimentos não são comprados aqui, não é nosso. Como que faz para gostar?"

"Todos aqui chamam a farinha de tapioca que vem [da secretaria] de tapioca isopor."
É possível fazer duas observações sobre as percepções dos alimentos tidas por aqueles que vivem o cotidiano da escola. Primeiro, admite-se, como nos sugere Fischler (1995), que a negação em consumir um alimento baseia-se não na fisiologia, mas em um sentimento moral e estético. Certos disso, não se pode confundir uma recusa local com uma repugnância universal. Afinal, o gosto por determinados produtos, de acordo com BrillatSavarin (2019), é “adquirido", e é preciso partir do processo de repetição para que se estabeleça socialmente mais do que biologicamente. Como segunda observação, apresenta-se o cuidado em não traduzir a repugnância alimentar em um menosprezo cultural, o que, para Contreras \& Gracia (2011), acontece quando uma visão etnocêntrica se impõe, ao classificar o outro não como diferente, mas como grupo social inferior.

No mesmo sentido, a docente 11 - ao expressar que "os alimentos não são comprados aqui, não é nosso" ou "como que faz para gostar?" demonstra que o grupo compartilha de códigos de pertencimento que levam o alimento a ser aceito ou não. Nas comunidades quilombolas, isso se torna mais evidente pelo fato de as fronteiras étnicas estabelecidas entre "nós" e os "outros" criarem elementos distintivos, como uma marca de cada

6 Na globalização, os hábitos alimentares têm-se transformado, substituindo-se produções locais por produtos ultraprocessados e de fácil acesso. A ação da chamada "era dos supermercados", no dizer de Popkin (2006), levou, nas últimas décadas, a consideráveis mudanças nos padrões de consumo dos povos locais. 
lugar (Barth 2005). Assim, segundo Fribourg (1996), consomem-se aqueles alimentos ou pratos que são considerados próprios do lugar em relação à comida dos outros; nas sociedades urbanizadas e industrializadas, os modelos culturais tendem a apagar a originalidade do modo de comer desses alimentos ou pratos.

A legislação do PNAE reforça o entendimento da relação entre alimento e cultura. Conforme o artigo 14, da Lei n. 11.947/2009, do total dos recursos financeiros repassados pelo governo ao PNAE, no mínimo 30\% (trinta por cento) deverão ser utilizados na aquisição de gêneros alimentícios diretamente da agricultura familiar, priorizando-se as comunidades tradicionais (Brasil 2009). No entanto, no momento da execução das ações, ainda se observa a presença de alimentos não identitários, como é o caso do mamão em Umarizal, que compôs o cardápio como sobremesa, mas foi oferecido como lanche, em forma de vitamina, para poder ser aceito pelos alunos. No topo das reivindicações do grupo da escola, está a vontade do quilombo de gerir a aquisição dos seus próprios alimentos. As insatisfações ocorrem porque o território oferece alimentos como pão, mandioca, feijão, arroz, abóbora, macaxeira, melancia, pupunha, laranja, limão, manga, acerola e outros, como as verduras e hortaliças, que não podem fazer parte do programa.

A ideia de aceitação do que é comestível ou não é construída em conjunto com saberes e habilidades técnicas transmitidos de geração a geração, com base nas experiências aprendidas. Os integrantes do grupo focal, ao afirmarem que "Todos aqui chamam a farinha de tapioca como tapioca isopor" (docente 8), "O nosso mingau de açaí é salgado, esse mingau papa, branco e doce ninguém come” (docente 10) e "O suco da merenda é conhecido como água da beira da estrada” (docente 12), dão ênfase às formas pela quais os alimentos podem ou não ser considerados adequados. Esse fato, conforme Douglas (1976), deve-se à forma pela qual as pessoas que comem se incorporam a um sistema de práticas materiais e simbólicas que o restante do grupo faz, ligando-as ao universo de relações e à continuidade global.

Como contraponto às preparações do cardápio escolar, os interlocutores da pesquisa mencionaram formas identitárias do comer na vila de Umarizal. As comidas lembradas com saudade foram aquelas feitas somente em momentos especiais, como o jabuti feito no leite da castanha, preparado no período da Semana Santa (quando ocorrem os festejos da Santíssima Trindade). A rememoração trouxe a dimensão emotiva da comida no período do festejo dos santos padroeiros da comunidade.

Quando questionados sobre quais alimentos expressam a cultura do quilombo e quais podem 
ser oferecidos na escola, houve consenso em torno da farinha de mandioca e da castanhado-pará, bem como de outros alimentos locais. As observações remetiam ao modo de fazer, aos utensílios utilizados, ao ambiente do preparo e, inevitavelmente, às relações de reciprocidade (Mauss 2008). Dessa forma, reforça-se a perspectiva de que os alimentos simbolicamente valorizados trazem em si um conjunto de elementos que estão entre a emoção, a memória e a experimentação, os quais definem sua aceitação.

A farinha de mandioca foi referida como um bom exemplo de cultura alimentar que não está no ambiente escolar. Para o grupo, Umarizal oferece a melhor farinha da região, por ser a mais torrada, por apresentar os caroços mais simétricos e por não conter sabor azedo.

Além disso, existe uma técnica que consideram própria do lugar, a qual consiste em retirar todo o tucupi ${ }^{7}$ da massa de mandioca e não a misturar com outros produtos antes de seguir para o forno. A farinha é consumida com todos os alimentos, inclusive frutas, café e, ainda, é matéria-prima para mingaus, como referido nas falas: "Aqui, a gente come a farinha [mandioca] com tudo" (docente 2); "Pupunha com farinha, manga com farinha, bacuri com farinha” (docente 17); “até melancia com farinha" (docente 20); e "O nosso mingau de açaí [salgado], tem gente que faz com farinha, mas a maioria prefere com arroz" (docente 4).

A castanha-do-pará é outro alimento do qual muitos sentem falta no cardápio da escola. Ela compõe várias preparações, por ser abundante na região. Ligada às proteínas, como na preparação de carne de caça - por exemplo, tatu na castanha, preguiça na castanha, jabuti na castanha -, a castanha-do-pará acaba ganhando status de símbolo de fartura ou abundância. Para o programa escolar, esse alimento foi citado estando associado à carne de gado e de frango, ou mesmo em mingaus, como posto na frase: "O gostoso mesmo é o mingau pateta, um mingau de farinha feito com castanha-do-pará”.

O PNAE, por ser o mais abrangente programa na área de alimentação e nutrição, tem, em suas cozinhas, um potencial papel impulsionador de espaços de resistência e de demarcação de identidades diante dos processos de mudanças pelos quais passa nosso sistema alimentar. Isso porque, de acordo com Maciel \& Castro (2013), os espaços de preparação de alimentos têm o poder de introduzir elementos novos na cozinha tradicional. São como parte de um projeto coletivo: estão em constante reconstrução e ressignificação. Dessa forma, é de se esperar que alimentos locais façam 
parte do cardápio escolar, mesmo que não seja possível replicá-los em sua forma originária em um ambiente institucional.

Para Hall \& du Gay (1996), assim como para Dietler (2007), a identidade cultural jamais é um produto acabado, mas algo em constante produção e transformação. No caso da alimentação escolar quilombola, valorar as experiências passadas e presentes na cozinha permite não somente uma conquista de direitos, mas também a continuidade de uma história de luta e de identidade de um povo.

\section{CONSIDERAÇÕES FINAIS}

A análise empreendida mostra que a alimentação escolar em territórios quilombolas tornou-se um desafio para a concretização dos objetivos do PNAE. As comunidades quilombolas fazem parte de um cenário rural, no qual estão presentes situações de fome, pobreza, conflitos sociais, territoriais e problemáticas ligadas à saúde e à nutrição (Melo \& H. Silva 2016; Oshai \& H. Silva 2013; Afonso et al. 2020). Garantir que os alunos façam uma refeição ao dia, nutricional, cultural e ambientalmente sustentável não é apenas uma bandeira contemporânea, mas também um projeto fundamental a ser executado pelas gerações futuras.
A partir do contato com a comunidade escolar da vila de Umarizal, foi possível demonstrar a descontinuidade da execução da política com a realidade dos alunos quilombolas. Nesse contexto, as discussões a respeito das dimensões culturais, no planejamento das atividades desenvolvidas pelos nutricionistas e pelas equipes do PNAE em território quilombola devem receber maior atenção do controle social, seja por parte dos que estão nos conselhos e associações, seja por parte da própria comunidade escolar.

Há um esforço de muitos para defender o PNAE e sua permanência na educação. O programa abrange o principal objetivo da política educacional, que é oferecer condições para a efetividade e o sucesso escolar, uma ação estratégica para equalizar as oportunidades de aprendizado dos escolares em todo o país. Assim, é preciso romper com o formato da alimentação oferecida para carentes e apropriarse do programa como indicador de qualidade da educação. A aprendizagem é o foco principal dos envolvidos no ambiente escolar e, para seu alcance, é fundamental oferecer um espaço saudável, seguro e acolhedor, com ações que mobilizem e potencializem o aprendizado do aluno. A alimentação escolar é parte desse processo. 


\section{REFERÊNCIAS}

Afonso, L. F. C., N. A. F. Corrêa, e H. P. Silva. 2020. Segurança alimentar e nutricional em comunidades quilombolas no Brasil: um balanço da literatura indexada. Segurança Alimentar e Nutricional 27:1-13. DOI: https://doi.org/10.20396/san.v27i0.8652861

Arruti, J. M. 2008. Quilombos, in Raça: novas perspectivas antropológicas. Organizado por O. Pinho, e L. Sansone, pp. 315-350. Salvador: Associação Brasileira de Antropologia/EDUFBA.

Barbot, J. 2015. Conduzir uma entrevista face a face, in A pesquisa sociológica. Coordenado por S. Paugam, pp. 102-123. Petrópolis: Vozes.

Barth, F. 2005. Etnicidade e o conceito de cultura. Antropolítica 19(2):15-30.

Bernard, H. R. 2011. Research methods in anthropology: qualitative and quantitative approaches. Lanham, MD: Rowman \& Littlefield.

Bouvard, V., D. Loomis, K. Z. Guyton, Y. Grosse, F. El Ghissassi, L. Benbrahim-Tallaa, N. Guha, H. Mattock, e K. Straif. 2015. Carcinogenicity of consumption of red and processed meat. The Lancet Oncology 16(16):1599-1600. DOI: https://doi.org/10.1016/S1470-2045(15)00444-1

Braga, V. 2004. Cultura alimentar: contribuições da antropologia da alimentação. Saúde em Revista 6(13):37-44.

Brandão, C. R. 2010. Repensando a pesquisa participante. São Paulo: Brasiliense.

Brasil. 1988. Constituição da República Federativa do Brasil de 1988. Brasília, DF: Senado Federal/ Centro Gráfico.

Brasil. 2009. Lei n. ${ }^{\circ}$ 11.947, de 16 de junho de 2009. Dispõe sobre o atendimento da alimentação escolar e do Programa Dinheiro Direto na Escola aos alunos da educação básica. Diário Oficial da União, de 17 junho de 2009. 
Brasil. 2012. Resolução CNE n. 8, de 20 de novembro de 2012. Define diretrizes curriculares nacionais para a educação escolar quilombola na educação básica. Diário Oficial da União, de 20 de novembro de 2012.

Brasil. 2013. Ministério da Educação. Resolução/CD/FNDE n. 26, de 17 de junho de 2013. Dispõe sobre o atendimento da alimentação escolar aos alunos da educação básica no Programa Nacional de Alimentação Escolar. Diário Oficial da União, de 18 de junho de 2013.

Brasil. 2017. Resolução CD/FNDE/MEC n. ${ }^{\circ}$ 1, de 8 de fevereiro de 2017. Altera o valor per capita para oferta da alimentação escolar do Programa de Alimentação Escolar - PNAE. Diário Oficial da União, de 9 de fevereiro de 2017.

Brasil. 2018. Lei n. 13.666, de 16 de maio de 2018. Altera a Lei n. 9.394, de 20 de dezembro de 1996 (Lei de Diretrizes e Bases da Educação Nacional), para incluir o tema transversal da educação alimentar e nutricional no currículo escolar. Diário Oficial da União, de 17 de maio de 2018.

Brillat-Savarin, J.-A. 2019. A fisiologia do gosto. São Paulo: Companhia das Letras.

Câmara Interministerial de Segurança Alimentar e Nutricional (CAISAN). 2017. Plano Nacional de Segurança Alimentar e Nutricional - PLANSAN 2016-2019. Brasília, DF: MDSA.

Carvalho, A. S., e D. Oliveira e Silva. 2014. Prospects of food and nutritional security in the Tijuacu Quilombo, Brazil: family agricultural production for school meals. Interface: Comunicação, Saúde Educação 18(50):521-532. DOI: http://dx.doi.org/10.1590/1807-57622013.0804

Certeau, M. 2009. A invenção do cotidiano. Artes de fazer. v. 1. Petrópolis: Vozes.

Hauvin, S., e N. Jounin. 2015. A observação direta, in A pesquisa sociológica. Coordenado por S. Paugam, pp. 124-140. Petrópolis: Vozes.

Contreras, J., e M. Gracia. 2011. Alimentação, sociedade e cultura. Rio de Janeiro: Fiocruz. 
Contreras, J. 1992. Alimentación y cultura: reflexiones desde la Antropología. Revista Chilena de Antropologia (11):95-111. DOI: http://dx.doi.org/10.5354/0719-1472.2011.17643

Cordeiro, M. M., E. T. Monego, e K. A. Martins. 2014. Overweight in Goiás' quilombola students and food insecurity in the families. Revista de Nutrição 27(4):405-412. DOI: https:// doi.org/10.1590/1415-52732014000400002

DaMatta, R. 1987. Sobre o simbolismo da comida no Brasil. O Correio da Unesco 15(7):22-23.

Dietler, M. 2007. Culinary encounters: food, identity, and colonialism, in The Archaeology of food and identity. Editado por K. C. Twiss, pp. 218-242. Carbondale: University of Southern Illinois.

Douglas, M. 1976. Pureza e perigo. São Paulo: Perspectiva.

Duarte, R. 2004. Entrevistas em pesquisas qualitativas. Educar em Revista 20(24):213-225.

Dufour, D. L., e R. L. Bender. 2013. Nutrition transitions: a view from Anthropology, in Nutritional Anthropology: biocultural perspectives on food and nutrition. Editado por D. L. Dufour, A. H. Goodman, e G. H. Pelto, pp. 372-382. Oxford, UK: Oxford University Press.

Fischler, C. 1995. El (h)omnívoro. El gusto, la cocina y el cuerpo. Barcelona: Anagrama.

Flandrin, J.-L., e M. Montanari. 2018. História da alimentação. São Paulo: Estação Liberdade.

Fribourg, J. 1996. Fêtes et cuisine traditionnelle en Espagne, in Cuisine, reflets des sociétés. Editado por M.-C. Bataille-Benguigui e F. Cousin, pp. 349-358. Paris: Sépia-Musée de l’Homme.

Fundo Nacional de Desenvolvimento da Educação (FNDE). 2015. Cadernos de estudos e atividades. Curso a distância sobre alimentação escolar indígena e quilombola. Brasília, DF. 
Fundo Nacional de Desenvolvimento da Educação (FNDE). 2019. Clientela atendida pelo Programa Nacional de Alimentação Escolar. Brasília, DF. Disponível em: http://www.fnde.gov.br/pnaeweb/publico/ relatorioDelegacaoEstadual.do. Acesso em: 10 jan. 2020.

Geertz, C. 1978. A interpretação das culturas. Rio de Janeiro: Zahar.

Halbwachs, M. 2013. A memória coletiva. Tradução de Beatriz Sidou. São Paulo: Centauro.

Hall, S., e P. du Gay (Eds.). 1996. Questions of cultural identity. London: SAGE Publications.

Instituto Brasileiro de Geografia e Estatística (IBGE). 2016. Pesquisa Nacional de Saúde do Escolar: 2015. Coordenação de população e indicadores sociais. Rio de Janeiro: IBGE.

Jaramillo, Y. M. 2012. Alimentación y cultura em el Amazonas. Bogotá: Ministério da Cultura.

Leite, I. B. 2008. O projeto político quilombola: desafios, conquistas e impasses atuais. Estudos Feministas 16(3):965-977. DOI: https://doi.org/10.1590/S0104-026X2008000300015

Maciel, M. E., e H. C. Castro. 2013. A comida boa para pensar: sobre práticas, gostos e sistemas alimentares a partir de um olhar socioantropológico. Demetra 8(1):321-328. DOI: https://doi.org/10.12957/demetra.2013.6648

Mauss, M. 2008. Da dádiva à questão da reciprocidade. Revista Brasileira de Ciências Sociais 23(66):131208. DOI: https://doi.org/10.1590/S0102-69092008000100008

Melo, M. F. T. e H. P. Silva. 2015. Doenças crônicas e os determinantes sociais da saúde em comunidades quilombolas do Pará, Amazônia, Brasil. Revista da ABPN7(16):168-189. Disponível em: www.abpnrevista. org.br/revista/index.php/revistaabpn1/article/view/103. Acesso em: 31 mar. 2020.

Montanari, M. 2013. Comida como cultura. São Paulo: SENAC. 
Nascimento, E. C., e G. A. D. Guerra. 2016. Do avortado ao comprado: práticas alimentares e a segurança alimentar da comunidade quilombola do Baixo Acaraqui, Abaetetuba, Pará. Boletim do Museu Paraense Emílio Goeldi. Ciências Humanas 11(1):225-241. DOI: http://dx.doi.org/10.1590/1981.81222016000100012

O’Dwyer, E. C. 2002. Quilombos: identidade étnica e territorialidade. Rio de Janeiro: FGV.

Oliveira, N. B., A. R. Santos, e E. A. Moreira. 2018. Programa Nacional de Alimentação Escolar e educação quilombola: a rede municipal de ensino de Vitória da Conquista/BA. Revista Amazônida 3(1):46-64. DOI: https://doi.org/10.29280/rappge.v3i1.4428

Oshai, C. M. A., e H. P. Silva. 2013. Áreas protegidas, populações desprotegidas: uma reflexão sobre a situação sócio-ecológica de populações quilombolas da Amazônia paraense. Áreas Protegidas e Inclusão Social: Tendências e Perspectivas 6(1):1039-1048.

Popkin, B. M. 2006. Global nutrition dynamics: the world is shifting rapidly toward a diet linked with non-communicable diseases. The American fournal of Clinical Nutrition 84(2):289-298. DOI: http:// dx.doi.org/10.1093/ajcn/84.1.289

Poulain, J.-P. 2004. Sociologias da alimentação. Os comedores e o espaço social alimentar. Florianópolis: UFSC.

Rodrigues, V. 2010. Programa Brasil Quilombola: um ensaio sobre a política pública de promoção da igualdade racial para comunidades de quilombos. Cadernos Gestão Pública e Cidadania 15(57):263-278. DOI: http://dx.doi.org/10.12660/cgpc.v15n57.3258

Sánchez Parga, J. 2010. El oficio de antropólogo. Crítica de la razón (inter)cultural. Quito: Abya-Yala.

Santana Filho, D. M., e L. S. S. Cerqueira. 2017. Planos educacionais e o enfoque educativo-ambiental na década dos afrodescendentes. Revista Entreideias 6(2):141-159. 
Santos, K. M. P., e M. E. P. E. Garavello. 2016. Uma análise agroalimentar: o caso dos agricultores quilombolas da Reserva de Desenvolvimento Sustentável Quilombos Barra do Turvo, SP. Redes 21(3):196-216. DOI: http://dx.doi.org/10.17058/redes.v21i3.7429

Silva, A. R. F. 2018. Políticas públicas para comunidades quilombolas: uma luta em construção. Revista de Ciências Sociais 1(48):115-128. DOI: https://doi.org/10.22478/ufpb.1517-5901.2018v1n48.27650

Silva, D. O., A. F. H. Guerrero, C. H. Guerrero, e L. M. Toledo. 2008. A rede de causalidade da insegurança alimentar e nutricional de comunidades quilombolas com a construção da rodovia BR-163, Pará, Brasil. Revista de Nutrição 21:83-87. DOI: http://dx.doi.org/10.1590/S1415-52732008000700008

Silva, E. K. P., D. S. Medeiros, P. C. Martins, L. A. Sousa, G. P. Lima, M. A. S. Rêgo, T. O. da Silva, A. S. Freire, e F. M. Silva. 2017. Insegurança alimentar em comunidades rurais no Nordeste brasileiro: faz diferença ser quilombola? Cadernos de Saúde Pública 33(4):e00005716. DOI: http://dx.doi.org/10.1590/0102$311 \times 00005716$

Silva, E. O., L. Amparo-Santos, e M. D. Soares. 2018. Alimentação escolar e constituição de identidades dos escolares: da merenda para pobres ao direito à alimentação. Cadernos de Saúde Pública 34(4):e00142617. DOI: https://doi.org/10.1590/0102-311x00142617

Sousa, L. M., K. A. Martins, M. M. Cordeiro, E. T. Monego, S. U. Silva, e V. P. Alexandre. 2013. Alimentação escolar nas comunidades quilombolas: desafios e potencialidades. Ciência \& Saúde Coletiva 18(4):987992. DOI: http://dx.doi.org/10.1590/S1413-81232013000400011

Souza, B. O. 2016. Aquilombar-se: panorama sobre o movimento quilombola brasileiro. Curitiba: Appris.

Souza, L. K. 2020. Recomendações para a realização de grupos focais na pesquisa qualitativa. PSI UNISC 4(1):52-66. DOI: http://dx.doi.org/10.17058/psiunisc.v4i1.13500 